\title{
Multiprofesyonel Eğitim: Avantajlar, Zorluklar ve Program Geliştirme Önerileri
}

\section{Multiprofessional Education: Advantages, Pitfalls and Program Development tips}

Mustafa DALOĞLU1 ${ }^{1}$, Yeşim ŞENOL ${ }^{1}$

${ }^{1}$ Akdeniz Üniversitesi Tıp Fakültesi, Tıp Eğitimi Anabilim Dalı

\section{ÖZET:}

Sağlık alanında bilginin hergün süratle artması, sağlık çalışanlarının giderek daha fazla uzmanlık alanlarına bölünmesine sebebiyet vermektedir. Bu durum bilginin entegre kullanımı için iş birliği ve takım çalışmasının önemini arttırmaktadır. Multiprofesyonel eğitim, farklı mesleki eğitim almış olan sağlık çalışanlarını henüz eğitim süreçlerinde iş birliği ve takım olma olgusuna teşvik etme potansiyeli nedeniyle artan bir değere sahiptir. Tüm avantajlarına rağmen multiprofesyonel öğeler içeren eğitim programları sınırlı sayıda uygulanabilmektedir.

Anahtar Kelimeler

Multiprofeyonel, eğitim, iş birliği, takım çalışması

Keywords:

Multiprofessional,

education, collaboration, team work
Başarılı bir multiprofesyonel eğitim progamı geliştirebilmek için pek çok faktör göz önünde bulundurularak planlama yapılmalıdır. Ortak bir eğitim programı uygulamanın önemli bir kolaylaştırıcısı program paydaşlarının ortak bir profesyonelizm anlayışına sahip olmalarıdır. $\mathrm{Bu}$ derlemede multiprofesyonel eğitimin tanımına, avantajlarına, programı oluşturmadaki zorluklarına ve program oluşturma yöntemlerine yer verilmiştir.

\section{Abstract}

The excessively growing data in the field of health sciences cause healtcare professionals to be subdivided into different specialties. In the name of providing high quality healtcare collaboration and teamwork gains significant importance. Multiprofessional education has an increasing value by means of its potential positive impact on promoting collaboration and teamwork among healthcare providers. Despite of its all advantages, its rate of implementation in to education programmes remains infrequent. There are plenty offactors, influencing the success of multiprofessional education, that has to be considered. A shared understanding of the concept of professionalism may facilitate multiprofessional education and collaboration. This review addresses to the definition, advantages, difficulties of multiprofessional education concept and approach to develop a multiprofessional education programme. 
Gönderme Tarihi / Submitted :13.12.2017

Kabul Tarihi / Accepted : 20.02.2018

\section{GIRİŞ:}

On dokuzuncu yüzyılın başlarında sağlık hizmetleri alanında tanımlanmış yalnızca iki meslek bulunmaktaydi: hekimlik ve hemşirelik. Günümüzde ise hastanelerde çalışan çeşitli terapistlerden teknisyenlere, işletmecilerden sosyal hizmetler uzmanlarına ve hatta palyaçolara kadar yüzlerce farklı görev tanımı yapılmaktadır. Tıp alanında baş döndürücü hızda yaşanan gelişmeler sebebi ile günümüzde hekimlerin tüm bilgiye hakim olmalarını imkansız kılmaktadır. Bu durum giderek artan branşlaşmanın altında yatan temel sebeptir. İleri derecede branşlaşma ilgili alanda kaliteli sağlik hizmeti sunumunu sağlamakla beraber diğer branşlarla ilgili konularda körlüklere sebep olabilmektedir. Güncel sağlık hizmetinde iş birliği ve takım çalışması giderek daha fazla önem kazanmaktadır. Multiprofesyonel eğitim (MPE) takım çalışmasını teşvik etmek için kullanılabilecek önemli bir araç olarak tanımlanmaktadır.

\section{Tanımlar}

Multiprofesyonel eğitimin tanımı ile ilgili ortak bir görüş bulunmamaktadır. Literatürde pek çok araştırmacı interprofesyonel (İPE) eğitimle olan farklarını değişik yönlerden ele alırken, bazı araştırmacılar bu iki yöntemi eşanlamlı olarak kullanmaktadır. Dünya Tıp Eğitimi Federasyonunun 1988'de yayınladığı Edinburg Deklerasyonunda Multiprofesyonel eğitim ve ekip çalışmasına vurgu yapılmıştır. Dünya Sağlık örgütünün aynı yıl yaptığı tanımlamaya göre multiprofesyonel eğitim, sağlık alanındaki farklı eğitim temellerine sahip öğrencilerin, eğitim süreçlerinin belli bir döneminde destekleyici, koruyucu, tedavi edici, rehabilite edici ve diğer sağlık ilişkili hizmetlerde iş birliğini teşvik etme amacı güden birlikte öğrenme sürecidir. (1) Barr, Birleşik Krallık İnterprofesyonel Eğitimi Geliştirme Merkezi'nin benimsediği tanımı, mevcut karmaşaya açıklık getirmek amacıyla önermiştir. Bu tanıma göre MPE iki veya daha fazla mesleğin eğitim süreçlerini herhangi bir sebeple beraber olarak sürdürdügü durumlardır. IPE ise iki veya daha fazla mesleğin aralarındaki iş birliğini ve sağlık hizmeti kalitesini arttırmak amacı ile birbirlerinden ve birbirleri hakkında öğrenmelerini benimseyen eğitim süreçleridir (2). Diğer bir görüş ise tanımlamanın yalnızca eğitim sürecine katılan mesleki grup sayısına göre yapılması gerektiğini savunmaktadır. $\mathrm{Bu}$ görüşe göre multiprofesyonel tanımı sağlık çalışanlarının iş birliğine vurgu yapan üç veya daha fazla mesleki alanın katıldığı, interprofesyonel terimi iki mesleki alanın katıldı̆̆ı eğitim süreçleri için kullanılmalıdır (3). Temel olarak MPE denilince farklı profesyonel disiplinlerin ortak bir konuyu aralarındaki iş birliği, iletişim ve farkındalığı arttırmak, problem çözme, karar verme ve takım çalışması becerilerini geliştirmek amacı ile kendi mesleki perspektifiden değerlendirme süreçleri anlaşılmaktadır (4).

Multiprofesyonel eğitimin temel hedefi işbirlirliği ile farklı yaklaşımların ortaya konulduğu çalışma ortamı yaratmaktır (5). Diğer potansiyel faydaları arasında takım ruhunu güçlendirmesi, özgüven ve kendini ifade yetisini geliştirmesi, ortak bir anlayış ve saygı çerçevesi çizmesi ve sağlık çalışanları arasındaki iletişimi güçlendirmesi sayılabilir (6). Beraber öğrenme mezuniyet öncesi ve sonrası tıp fakültesi ve hemşirelik öğrencilerinin iletişim becerilerini geliştirirken, bilimsel yaklaşım dağarcı̆̆ını 
genişletmektedir (7). Tüm bu avantajlara ve hatta bazı ülkelerde verilen devlet desteklerine rağmen günümüzde başarılı MPE programı sınırlı sayıda merkezde, sınırlı düzeyde uygulamaya geçebilmektedir (8). Uygulamanın başlatıldığı merkezlerde ise sürdürülebilirlik problemleri gözlemlenmektedir.

\section{Multiprofesyonel Eğitim}

\section{Programı Geliştirmedeki Zorluklar}

MPE organizasyonu yoğun emek ve zaman gerektirir. Eğiticilerin motivasyonları başka önceliklerinin olması ve uygulamanın etkinliğinden duyulan şüpheler nedeni ile düşük kalabilmektedir. Öte yanda bazı profesyoneller alan bilgilerini koruma ve diğer disiplinler ile paylaşmama eğiliminde olabilmektedir. Sonuç olarak farklı disiplinlerden öğrenci kabul etme konusunda zorluklar yaşanmaktadır. Titiz bir planlama sürecine rağmen takım elemanlarının beklenmedik klinik sorumlulukları nedeniyle iptal edilen oturumlar sürdürebilirlik sorunları olarak sıralanabilir. Yaşanan bir diğer zorluk ise öğrencilerin farklı disiplinlerin müfredatına ait bilgilere ilgisiz kalmalarıdır (9). MPE ve İPE uygulamalarını kendi mesleki eğitimlerinden sapma olarak görebilmektedirler. İletişim problemleri sağlık hizmetlerinde yaşanan hataların önemli bir sebebidir (10). MPE sağlık hizmetinde iletişimi geliştirmekte etkili bir araç olarak görülmekle beraber, iletişimdeki sorunlar MPE'in uygulanması için engel teşkil edebilir. Ders programı oluşturmadaki sorunlar, farklı öğrenen grupları arası uyuşmazlıklar, farklı öğrenme ve ölçme metodları, öğrenen ve eğitici özveri eksiklikleri, planlama ve kaynak zorlukları, grup çalışmaları için uygun fiziki şartlardaki yetersizlikler MPE uygulamalarındaki diğer güçlükler arasında sayılabilir (3).

Parsell \& Bligh program oluşturma ve organizasyon

sürecindeki

zorlukların

kaçınılmaz olduğunu bildirmiştir (11). Ancak tüm zorluklar arasında aşılması en güç olanı paydaş tutumlarının değiştirilmesidir. Sosyal kimlik teorisi gruplar arası davranış kalıplarını, grup üyeliği ve grup olma olgusunu, bireyin kendisini neden ve ne zaman bir grubun parçası olarak tanımladığını ve başkalarının tutumlarını benimsediğini açıklamaya çalışan temel psikolojik bir kuramdır (12). Sosyolojiye göre grup belirli karakteristik özellikleri paylaşan, birbiri ile etkileşim halinde olan, grup elemanı olarak beklenti ve yükümlükleri kabul eden ve ortak bir kimliği paylaşan bireyler topluluğudur (3). Bireyler toplumda pozitif sosyal kimliklere özenmektedir. Pozitif sosyal kimliğin tespitinin altında bireyin ait olduğu grup ile diğer grupların karşılaştırılması yatmaktadır. Farklı yöntemlerle bireyler sosyal kimliklerini değiştirebilir. Birey daha yüksek statülü bir grubun üyesi olmaya çalışabilir. Böyle bir durumda eski grubun statüsünde bir değişiklik olamazken yeni grup üyelerinin bu katılıma direnç göstermesi söz konusu olabilir (3). Profesyoneller kendilerinden daha düşük statülü olarak gördükleri profesyonellerle işbirliği yapmaları halinde kendi statülerini kaybetme kaygısı taşıyabilirler. Kendilerini farklı mesleki temelleri olan bireylerden kurulu bir takımın parçası olarak göremeyebilirler. $\mathrm{Bu}$ durumda aynı zamanda kendi mesleki grubunun arkasında saklanma ve güçlü kalma eğilimi gösteren bir pozisyon benimsemiş olurlar. Sorunların çözümlenmesinde iş birliği yapmak bir seçenek olarak kabul edilebilir. Sağlık hizmetlerinin hekimler, hemşireler ve diğer sağlık çalışanlarının iş birliği ile yürütüldüğü birçok kurum bulunmaktadır. Birlikte çalışmanın benimsendiği sağlık kuruluşlarında yatış sürelerinin daha kısa, mortalite oranlarının daha düşük olduğunu 
gösteren yayınlar bulunmaktadır (13). Diğer yandan iş birliğinin eksikliği sağlık hizmetinin verilişinde yetersizliklere sebep olmaktadır. Birlikte çalışmanın belirgin avantajlarına rağmen sosyal kimlik ilişkili tutumlar gerek eğitim programlarında gerekse sağlık hizmetlerinin sunumunda iş birliği için engel teşkil etmektedir (3). Farklı uzmanlık alanları gibi mesleki gruplar arası rekabet özellikle kaynaklar azaldığı durumlarda daha belirgin olmaktadır. Bu nedenle kaynaklar konusunda kimin sorumlu olacağ1, itibarı kimin alacağ1 gibi soruların iyi yanıtlanması gerekmektedir (14). Ayrıca mesleki gruplar arası etik ve ahlaki anlayış farklılıklarının da bulunabileceği göz önünde bulundurulmalıdır. Allport'un temas hipotezine göre sosyal gruplar arası önyarg1 ve sürtüşmeler grupların uygun şartlar altında etkileşmesi ile hafifletilebilir (15). İşleyen bir MPE programı için bu etkileşim önemli rol oynamaktadır. Aksi taktirde programın tamamının etkisi parçalarının toplamından az olmaktadır (16). MPE kötü planlanması halinde mesleki gruplar arası farkları olumsuz anlamda pekiştirebilir (17).

MPE programlarının geliştirilmesinde mesleklerin gelişim evrelerinde yaşanılan süreçlerin, sorunların vb. olumsuz etkileri olabilir. Hemşirelik ve hekimlik uygulamaları arasındaki ilişki bu durumlara örnek olarak gösterilebilir. Hemşirelik mesleğinin imajının kökleri Victoria dönemine, Florence Nightingale'e uzanmaktadır (18). O dönemlerde hemşirelerin kendilerini alçakgönüllükle ve sevgiyle hastalarına ve onların iyileşmesine adamaları beklenirdi. Hastanelerde hekimlerin direktiflerini takip etmeleri istenirdi. Horder kendi deneyimlerine dayandırdı ̆̆ 1950'ler Londra'sında hekimlerin hemşireler ve diğer işçilerler ile konuşmasının son derece nadir bir durum olduğunu belirtmiştir. İletişimin daha çok birim sorumluları aracılığı ile veya yazılan ve sıklıkla okunması unutulan notlar aracılığı ile yapıldığını bildirmiştir (19). Bu durum şüphesiz iletişim problemine dikkat çekmekle beraber meslekler arası gözetilen statü farkının bir sonucudur. Günümüzde hemşireliğin yükselen eğitim seviyesi, görev tanımındaki özgürleşmelerle geçirdiği kökten değişime rağmen, bazı hemşirelerin halen düşük benlik saygısına sahip olduğunu gösteren yayınlar mevcuttur. Hemşirelerin düşük benlik saygısı hemşirelik mesleğinin de imajını olumsuz yönde etkilemektedir (18). Bu durum pek çok başarılı hemşireye rağmen eski adet ve klişelerin, iş birliği olgusuna olumsuz etki etmesine sebep olmaktadır (20).

\section{Multiprofesyonel Eğitim \\ Programının Uygulanması}

Daha önce tariflenmiş olan tüm zorluk ve engeller şüphesiz MPE'e harcanacak zaman ve çabanın daha karlı amaçlar için harcanabileceğini düşünenlerin MPE ile ilgili kuşkularının haklı çıkmasına hizmet edecektir. MPE'in bazı kurumlar için uygulanabilirliğinin düşük olması yanında, mevcut eğitim programlarına entegre etmek isteyen hevesli ve enerjik kurumların da olması şaşırtıcı olmayacaktır.

Harden MPE'nin uygun şekilde planlanıp kullanılması halinde gerçekten etkin bir yöntem olduğuna vurgu yapmaktadır. Ancak uygun şekilde planlanıp uygulanmadığı zaman birçok sorunla karşılaşılabileceğini belirtmektedir (8). MPE'nin uygun kullanımı için gereken özellik ve şartlar dört grupta toplanmaktadır (11). Bunlar:

1) Mesleki gruplar arası ilişkiler (kişilerin inanış ve değer yargıları)

2) İşbirliği ve takım çalışması (gereken yetenek ve bilgi birikimi) 
3) Roller ve sorumluluklar (kişilerin gerçekte ne yaptığ 1 )

4) Hasta, mesleki uygulama ve kişisel gelişim kazanımları (gerçekte olan)

Harden'a göre başarılı uygulamanın üç boyutu mevcuttur. $\mathrm{Bu}$ boyutları MPE'in içeriği, hedefleri ve ele alınış biçimi olarak tanımlamıştır. İçerik ile ilgili belirlenmesi gereken ilk özellik MPE'in eğitim programının hangi fazında uygulanacağıdır. Dolayısıyla içerik farklı sevilerde farklı olmak zorundadır. Eğitim programı hazırlanırken 'Ne zaman?" sorusunun cevabı aranmalıdır. $\mathrm{Bu}$ konuda farkl1 görüşler mevcuttur. Pirrie ve ark. Mezuniyet öncesi eğitim düzeyinde MPE'e düşük ilgi tespit etmiştir. Bunun altında yatan neden olarak eğitimin bu fazında MPE'in uygulama zorluklarını göstermişlerdir ve her mesleki kolun MPE öncesi kendi mesleki kimliğini ve özgüvenini geliştirmesi gerektiğini belirtmişlerdir (21). Buna karşın öğrencilerin beraber öğrenme ile mezuniyet öncesi programlarda erken dönemde oturumlar ve temalar aracılığı ile tanıştırılmasını öneren araştırmacılar bulunmaktadır (22). Horder uygun mesleki tutumların telkin edilmesinin önemine vurgu yapmıştır ve önyargıların gelişmesini engellemek için MPE'in erken dönemde programa dahil edilmesini önermiştir (23). İçerik ile ilgili olarak MPE'in kurgusu önem arz etmektedir. İçeriğe göre eğitimin birinci basamak, uzmanlık dalı kliniğgi veya genel olarak hastane ortamı tercihi yapılmalıdır. Konu seçimi içeriğin diğer tarafinı oluşturur. Bunun yanında öğrenme yaklaşımı tercihi içeriğe en iyi hizmet edecek şekilde seçilmelidir. Küçük grup çalışmaları, konferans tipi dersler, uzaktan eğitim ve probleme dayalı öğrenim (PDÖ) örnek olarak gösterilebilir. PDÖ multiprofesyonel eğitimde takım çalışmasını teşvik etmesinden ve rekabeti baskılamasından ötürü ilgi çekici bir konumdadir (24).

Ulaşılmak istenilen çıktı iş birliği ve takım çalışması olduğundan hedeflerin de çıktıları destekleyen nitelikte seçilmesi uygun bir yaklaşım olacaktır. Harden'a göre hedeflerin özellikleri dört ana başlık altında toplanabilir (8).

1)Farklı mesleki alanların çekirdek yetkinlikleri göz önünde bulundurmak.

2)Çok yönlü beceri sergileyebilen gerektiğinde kendi profesyonel sınırı ötesinde sorumluluk alabilen ekip elemanı yetiştirmek;

3)Farklı mesleki alanların bakış açısını özümseme ve mesleki rollerini anlama ve rollerine saygı gösterme tutumlarını geliştirmek; 4)Sağlık hizmetlerinde farklı meslek gruplarının takım halinde çalışmasını kolaylaştırma amacı ile iletişim ve iş birliği becerilerine vurgu yapmaktır.

Üçüncü boyut olarak Harden MPE'nin ele alınış biçimine değinmiştir. Eğitim sürecinde MPE uygulamasında spektrumun bir ucunda izole eğitim sistemlerini diğer ucunda ise transprofesyonel eğitim süreçlerini örnek göstermiştir. Spektrumu 11 basamaklı bir süreç olarak tariflemiştir (8).

1. İzolasyon: Spektrumun bu ucunda diğer mesleki alanlarla hiç temas yoktur. Müfredatta diğer alanlarla ilgili konulara yer verilmesi planlanmaz. Ortak konular ancak rastlantisal olarak bulunabilir.

2. Farkındalık: $\mathrm{Bu}$ seviyede farklı mesleki alanlar arasında resmi bir iş birliği yoktur. Ancak farklı alanlar birbirlerinin rollerinin farkındadır. Program dahilinde bu farkındalık bir oranda öğrencilere yansıtılabilir.

3. Konsültasyon: Bu aşamada halen ayrı olan programların ortak başlıklardaki birbirleri ile ilgili kavrayışları daha üst düzeydir. Farklı 
alanların birbiri ile temasının başladığı seviyedir. 4. İç içe geçme: Beraber öğrenmenin olmadığ1 bu basamakta farklı mesleki alanların birbirlerinin rollerini anlama konusunda yoğun çaba sarfetmesi sözkonusudur. Farklı alan eğiticileri eğitim programına dahil edilmektedir. 5. Geçici koordinasyon: Beraber öğrenmenin başlamasından önceki son basamaktır. Ders programinda ortak konulara iki veya daha fazla mesleki grubun katılımının olduğu bazı dersler yer alır. Bu durum önerilmekle beraber amaca sınırlı olarak hizmet etmektedir Beraber öğrenme: Bu seviyede ek olarak programa dahil olan farklı mesleki alanlar arasında etkileşim mevcuttur.

6. Korelasyon: MPE'in bu basamağında vurgu hala tekprofesyonel eğitime(TPE)yapılmaktadır. Ancak yine de iyi tanımlanmış MPE oturumları mevcuttur. Kabaca MPE persfektivinde yapilan TPE olarak tanımlanabilir.

7. Övgüler: Bu aşamada programın vurgusu hem MPE hem de TPE'dedir. İki yöntemin de güçlü yönlerinden fayda sağlamak amaçlanmaktadır. Müfredatta farklı mesleki alanlar birbirlerinin rollerinin önemlerini vurgularlar.

8. Multiprofesyonel Eğitim: $\mathrm{Bu}$ basamakta vurgu MPE üzerinedir. Ancak her mesleki alan konuya kendi bakış açısı ile yaklaşmaktadır. Örnek olarak PDÖ oturumunda öğrenciler sorunun üstesinden gelmek için ortak bir yaklaşım sergilerler ancak herkes kendi mesleki açısından sürece katkı sağlar.

9. İnterprofesyonel eğitim: İPE de farklı mesleki alanlardan olan öğrenciler arasında ayrım yapılmaz. Öğrenciler konuya kendi mesleki bakış açılarının yanı sıra diğerlerinin bakış açılarıyla da yaklaşırlar. $\mathrm{Bu}$ süreçlere örnek olarak role-play şeklinde planlanan oturumlar verilebilir.

10. Transprofesyonel eğitim: Spekturum bu ucunda MPE klinik uygulamalarda yer almaktadır. Eğitimin sınıftan çıkıp gerçek hayat içerisinde sürdüğü, öğrencinin sağlık hizmeti sağlayan bir takımın parçası olduğu süreçleri ifade eder.

Carr ve ark. Multiprofesyonel beceri eğitimi programı geliştirmede 12 pratik öneri sunmuştur (25). Bunlar:

1. Programın gelişimine zemin olarak yerel kanıtlar gösterilmesi. Gerekli maddi ve manevi destek için fakülte üyelerinin değişimin gerekli olduğuna inanmalarının sağlanması.

2. Ekibin farklı disiplinlerin temsilcilerinden oluşturulması. Akılcı seçilmiş olan temsilciler okul genelinde destek sağlacak taraflar olacaktır. 3. Programa ve eğiticilerden oluşan multiprofesyonel takıma liderlik edecek koordinatörlerin atanması. $\mathrm{Bu}$ sürecin tüm disiplinlerin desteğini alabilecek, uygun eğiticileri işe dahil edebilecek, oturumların koordinasyonunun sorumluluğunu üstlenebilecek bir rol model ile yürütülmesi programın başarısına katkı sağlayacaktır.

4. Maddi kaynakların merkezi olmasının sağlanması. $\mathrm{Bu}$ sayede programa dahil olan disiplinler arası eşitlik yaratılarak programın sürdürülebilirliği sağlanır.

5. Araştırma ve geliştirme firsatlarının eğiticiler ve çalışma ekibi ile tartışılması.

6. Eğiticilerin eğitimi.

7. Tüm öğrencilerin benzer öğrenme tecrübelerine sahip olmaları için eğitimlerin ve eğiticilerin standardizasyonun sağlanması.

8. Eğitimler sonrası tüm öğrencilerin temel bir yeterlik seviyesine ulaştığının garanti altına alınması.

9. Öğrencilerin klinik tecrübe ve geribildirim verebilmeleri için firsatlar yaratılması. Açık Geribildirimlerle sürekli veya tekrarlayan pratiklerin yeterlik gelişiminde önemli katkıları bulunmaktadir. 
10. Öğrenilen beceriler için değerlendirme stratejilerinin belirlenmesi

11. Tüm paydaşlardan geri bildirimlerin alınması ve geri bildirimler doğrultusunda hareket edilmesi.

12. Tüm paydaşların sürece dahil edilmesi ve düzenli olarak bilgilendirilmesi.

\section{Sonuç}

Multiprofesyonel eğitim programı geliştirmede pek çok engel teşkil edecek faktörler bulunsa da içerik ve hedeflere uygun bir yaklaşım program başarısını sağlayacaktır. Aksi taktirde program fayda sağlamaktan uzaklaşıp sürdürülemez bir hal alabilir. Ortak bir profesyonalizm anlayışı, MPE'de işbirliği ve sorumluluk paylaşımını kolaylaştıracaktır.

\section{Kaynaklar}

1. World Health Organization, Learning Together to Work Together for Health, Report of WHO study Group on Multiprofessional Education for Health Personnel the Team Approach, Technical report series 769 Geneva, 1988, WHO. The World Health Organization

2. Barr H. Interprofessional Education. Today, Yesterday and Tomorrow. A Review. London: The Learning and Teaching Support Network for Health Sciences and Practice; 2002

3. Roodbol PF. Multiprofessional education to stimulate collaboration: a circular argument and its consequences. GMS Z Med Ausbild. 2010;27(2):Doc28. DOI: 10.3205/zma000665

4. Sherwood G, Thomas E, Bennettee DS, Lewis P. A teamwork model to promote patient safety in critical care. Crit Care Nurs Clin North Am. 2002;14(4):333-340.DOI:10.1016/S0899-
$5885(02) 00020-5$

5. Loxley, A. Collaboration in Health and Welfare: Working with Difference. London: Jessica Kingsley Publishers, 1997

6. Mires G, Williams F, Harden R, Howie P. The benefits of a multiprofessional education programme can be sustained. Medical Teacher 2001:23;300-304.

7. Harden RM. AMEE guide No. 12: Multiprofessional education: Part 1 - effective multiprofessional education: a threedimensional perspective, Medical Teacher, 1998:20:5,402-408

8. Finch J. Interprofessional education and teamworking: a view from the education providers. BMJ. 2000;321(7269):1138-1140. DOI:10.1136/bmj.321.7269.1138

9. Wahlström O, Sandén I, Hammar M. Multiprofessional education in the medical curriculum. Med Educ. 1997;31(6):425-429. DOI:10.1046/j.1365-2923.1997.00669.x

10. Primmer D. Teamwork and communication. J Courtin Educ Nurs. 2009;40(7):294-295.

11. Parsell G, Bligh J. The development of a questionnaire to assess the readiness of health care students for interprofessional learning (RIPLS). Med Educ 1999;33:95 \pm 100 .

12. Taifel H, Turner JC. An integrative theory of intergroup conflicts. In Worchel S, Austin LW (Hrsg). Psychology of Intergroup Relations. Chicago: Nelson- Hall; 1986.

13. Rafferty AM, Ball J, Aiken LH Are teamwork 
and professional autonomy compatible, and do they result in improved hospital care? BMJ Quality \& Safety 2001;10:ii32-ii37.

14. Kinston W. Hospital organisation and structure and its effect on inter-professional behaviour and the delivery of care. Soc Sci Med. 1983;17(16):1159-70.

15. Marletta G, Sarli L, Caricati L, Mancini T. Intergroup contact and team functioning among nursing students: the mediation role of intergroup anxiety. Acta Biomed. 2017 Jul 18;88(3 -S):37-42. doi: 10.23750/abm.v88i3 -S.6612.

16. Eva KW. Teamwork during education: the whole is not always greater than the sum of the parts. Medical Education 2002, 36, 314-6

17. Priest H, Sawyer A, Roberts P, Rhodes SA. survey of interprofessional education in communication skills in healthcare programmes in the UK. Journal of Interprofessional Care 2005, 19, 236-50.

18. Ten Hoeve Y, Jansen G, Roodbol P. The nursing profession: public image, self-concept and professional identity. A discussion paper. Journal of Advanced Nursing 2013:70(2), 295309. doi: 10.1111/jan.12177

19. Horder, J. Leadership in a multiprofessional context. Medical Education 2000;34:203 \pm 205

20. Flechter K. Image: Changing how women nurses think about themselves. Literature review. J Adv Nuirs. 2007;58(3):207-215. DOI:10.1111/j.1365-2648.2007.04285.x

21. Pirrie A, Wilson V, Harden RM, Elsegood
J. Promoting cohesive practice in health care, Medical Teacher, 1998:20, pp. 409 416.

22. Areskog NH. The need for multi-professional health education in undergraduate studies. Med Educ 1988;22:251 \pm 2

23. HORDER J. The Centre for the Advancement of Interprofessional Education, Education for Health, 1996:9(3), 397 \pm 400

24. Brandon JE, Majumdar B. An introduction and evaluation of problem-based learning in health professions education, Family Community Health, 1997:20(1), pp. $1 \pm 15$

25. Carr SE, Celenza A, Lake F. Establishing an integrated multiprofessional skills training programme, Medical Teacher, 2010:32:1, 41-45, DOI:10.3109/01421590902810786 